\title{
Pautas para la vacunación en caninos y felinos en Uruguay
}

\section{Guidelines for vaccination in dogs and cats in Uruguay}

Gabriela Franco' ${ }^{1}$ 0000-0001-8680-0014

Rodrigo Puentes ${ }^{1 *}$ 0000-0002-4618-9721

${ }^{1}$ Área Virología, Dpto. Ciencias Microbiológicas, Facultad de Veterinaria, Universidad de la República. Lasplaces 1550.

Montevideo, Uruguay.*Email: rpuentes@fvet.edu.uy

Veterinaria (Montevideo) Volumen 56

Nº 213 (2020 Ene - Jun) e20205621305

\section{Resumen}

La vacunación es una herramienta ampliamente utilizada en medicina veterinaria para la prevención de determinadas patologías infecciosas en animales de compañía. Debido a la necesidad de unificar conocimientos científicos y recomendaciones sobre su uso, se elaboró esta guía con pautas basadas en la epidemiología de las enfermedades en Uruguay y la disponibilidad de vacunas comerciales para su implementación. Las vacunas de pequeños animales se dividen en esenciales y opcionales. Las esenciales previenen enfermedades de distribución mundial potencialmente mortales y deben ser administradas a todos los animales, apuntando a lograr una inmunidad poblacional. Las vacunas opcionales deben ser administradas a los animales cuya área geográfica, medio ambiente o estilo de vida los exponga a enfermedades específicas. Existen varios factores que pueden interferir con la inmunización activa, entre ellos se encuentra los anticuerpos maternales en cachorros, las parasitosis concomitantes, el uso de ciertos fármacos y la senescencia del sistema inmune. Las vacunas son productos biológicos seguros, pero no están exentos de provocar reacciones adversas en el organismo en situaciones muy particulares, siendo generalmente además autolimitantes. En esta guía se proponen diferentes planes de vacunación para los animales de compañía según su edad, así como se establecen pautas para la vacunación en refugios de animales. La misma se realizó considerando las últimas recomendaciones internacionales, apoyándose en el conocimiento científico disponible y la realidad del Uruguay en cuanto a la epidemiología de las enfermedades. De esta manera, se pretende auxiliar a los profesionales veterinarios para hacer el mejor uso de las vacunas, de forma optimizada y segura.
Recibido: 04/09/2019

Aceptado: 12/12/2019 (cc) EY-NO

\section{Abstract}

Vaccination is a widely used tool in veterinary medicine for the prevention of defined infectious diseases in pets. Due to the need of unifying scientific knowledge and recommendations on its use, this guide was developed with guidelines based on the epidemiology of diseases in Uruguay and the availability of commercial vaccines for its implementation. Small animal vaccines are divided into core and non-core. The core vaccines prevent from worldwide distributed life-threatening diseases and must be administered to all animals, aiming to achieve herd immunity. Non-core vaccines should be administered to animals whose geographic area, environment or lifestyle, exposes them to specific diseases. There are several factors that could interfere with active immunization, including maternal antibodies in puppies, concomitant parasitosis, the use of certain drugs and senescence of the immune system. Vaccines are safe biological products, but they are not exempt from causing adverse reactions in particular situations, though they usually are self-limiting. This guide proposes different vaccination plans for pets according to their age, as well as a guidelines for shelters vaccination. It was carried out considering the latest international recommendations, based on the available scientific knowledge and the epidemiological information in Uruguay. In this way, it is intended to help veterinary professionals to make the best use of vaccines, in an optimized and safe way.

Keywords: Immunization, Canines, Felines, Immunity, Shelters.

Palabras clave: Inmunización, Caninos, Felinos, Inmunidad, Refugios. 


\section{Introducción}

La vacunación es un método eficaz y seguro para prevenir enfermedades infecciosas en los animales de compañía. Un censo realizado en el 2017 indica que en nuestro país tenemos 1.750 .000 perros y 690.000 gatos aproximadamente. La vacunación es importante, no solo para proteger a ese animal en sí, sino que para establecer una "inmunidad poblacional”, la cual es fundamental para la prevención de brotes de enfermedades, al bajar el número de animales susceptibles a dicha patología. Se estima que en los países desarrollados sólo un 30-50\% de los pequeños animales son vacunados, calculándose un porcentaje menor en los países en vías de desarrollo como el nuestro. Es un consenso internacional priorizar aumentar el número de mascotas vacunadas, en lugar de sobrevacunar los individuos, aumentando con esta estrategia la mencionada inmunidad poblacional, disminuyendo así la prevalencia de las enfermedades infecciosas prevenibles con vacunación (Day et al., 2016). Las vacunas pueden ser divididas en esenciales y opcionales. Las esenciales son aquellas vacunas que previenen enfermedades de distribución mundial potencialmente mortales y deben ser administradas a todos los animales independientemente de las circunstancias o situación geográfica a intervalos recomendados. Las vacunas esenciales para caninos protegen frente a la infección por Parvovirus $\mathrm{Ca}$ nino tipo 2 (CPV-2), Virus de Distemper Canino (CDV) y Adenovirus Canino tipo 1 (CAV-1). Las vacunas esenciales para los gatos son las que protegen contra el Virus de la panleucopenia felina (FPV), Calicivirus felino (FCV) y Herpesvirus felino-1 (FHV-1). En las zonas del mundo donde la infección por el virus de la rabia es endémica, la vacunación contra este agente debe ser considerada esencial para ambas especies, incluso si no hay ningún requisito legal para la vacunación de rutina para la protección tanto de la mascota como de la salud pública. Las vacunas opcionales deben ser administradas a los animales cuya área geográfica, medio ambiente o estilo de vida los exponga a enfermedades específicas. Las vacunas opcionales para caninos previenen la infección por Leptospira interrrogans, Bordetella bronchiseptica, Borriela burgdorferi, Virus de la Parainfluenza e Influenza. Las vacunas opcionales para felinos protegen frente a Virus de la leucemia felina (ViLeF), Virus de la inmunodeficiencia felina (ViF), Chlamydia felis, Bordetella bronchiseptica. La vacunación frente al Coronavirus canino $(\mathrm{CoC})$ y la peritonitis infecciosa felina (PIF) no son recomendadas por los organismos internacionales (Day et al., 2016).

Los anticuerpos maternales (MDA) interfieren significativamente con la vacunación, especialmente las esenciales MLV ("modified live vaccines" o vacunas vivas modificadas), cuando son administradas en la vida temprana de los cachorros caninos y felinos (Day MJ, 2007). Sin embargo, cuando la última dosis de vacuna se administra a las 16 semanas de edad o más, es esperable que los MDA se encuentren en niveles suficientemente bajos como para que la inmunización activa sea efectiva en la mayoría de los cachorros (Day et al., 2016).

La administración de una vacuna en un animal implica necesariamente un gasto energético para que se establezca una res- puesta inmune satisfactoria. Por tanto, para que esta respuesta generada sea eficiente y robusta, siempre es ideal que el animal a ser vacunado se encuentre en buen estado de salud. Sin embargo, frente a situaciones de riesgo de contraer alguna enfermedad infecciosa prevenible por vacunación, se debe poner en la balanza los beneficios de adelantar la vacunación del animal, aún en situaciones consideradas "sub óptimas" de salud. Cabe destacar que las vacunas son productos biológicos, y como tales pueden provocar reacciones adversas en el organismo (Welborn et al., 2011), razón por la cual hoy en día se tiende a reducir la "carga vaccinal" por animal, con el fin de minimizar la posibilidad de estas reacciones, ya que el exceso de vacunación no inducirá una "mejor" inmunidad individual (Day et al., 2016).

En nuestro país la mayoría de las vacunas se comercializan de forma multivalente, dificultando la diferenciación entre vacunas esenciales y opcionales en el momento de la administración. Por otro parte, no se conoce a ciencia cierta la incidencia y/o prevalencia de la mayoría de los agentes infecciosos presentes en las poblaciones caninas y felinas de Uruguay. En ese sentido nuestro grupo ha realizado algunos aportes sobre situación de la enfermedad, aislamientos virales y respuesta inmune contra Parvovirus canino (Machin et al., 2013; Puentes et al., 2012; Franco y Puentes, 2011; Eliopulos et al., 2010; Puentes et al., 2010) y rabia canina (Puentes et al., 2016; Eliopulos et al., 2013; Moreno et al., 2012). Por otro lado, otros grupos de investigación de Uruguay, han caracterizado genéticamente las cepas circulantes tanto de Parvovirus (Maya et al., 2013: Pérez et al. 2012) como de Distemper canino (Panzera et al., 2015; Sarute et al., 2014) en el país. Sin embargo, se necesitan más investigaciones que incrementen los conocimientos sobre afecciones causadas por bacterias y virus que afectan a estas especies en el país frente a los cuales existen vacunas disponibles. En ese contexto y considerando la falta de conocimiento nacional, esta guía pretende ser una ayuda para el Médico veterinario al momento de diseñar un plan de vacunación canina o felina, sin plasmar verdades absolutas.

\section{Tipos de vacunas existentes}

Las vacunas se pueden dividir en infecciosas y no infecciosas. La mayoría de las vacunas utilizadas en los animales de compañía contienen organismos atenuados, es decir en estado infeccioso pero con su virulencia reducida ("modified live virus" - MLV o vacunas vivas atenuadas). Los patógenos se encuentran intactos y viables, estimulan la inmunidad induciendo una infección de bajo nivel al replicarse en el animal sin producir una patología tisular significativa o signos clínicos de enfermedad infecciosa. Las vacunas infecciosas presentan la ventaja de inducir una inmunidad más efectiva en sitios anatómicos importantes cuando son administradas de forma parenteral, y producen una inmunidad celular y humoral más robusta. Algunas vacunas infecciosas se presentan para ser administradas en las mucosas directamente (intranasales u orales) y por lo tanto, son más efectivas en 
estimular una inmunidad protectora a nivel local (inmunidad de mucosas). Las vacunas con vectores recombinantes también se clasifican como infecciosas aunque el organismo vector no sea importante o patogénico para la especie a vacunar. Si el animal a vacunar no presenta anticuerpos calostrales, generalmente una sola dosis de este tipo de vacunas (MLV) es suficiente para estimular una inmunidad protectora (Day et al., 2016; Flores, 2007). Sin embargo, estas vacunas son menos estables, por lo que deben mantenerse estrictamente a temperaturas entre 2 y $8{ }^{\circ} \mathrm{C}$ y una vez reconstituidas debe evitarse su exposición a agentes químicos que puedan inactivarlas. Estas vacunas se presentan usualmente en el mercado en forma liofilizada, debiendo usarse en un periodo no mayor a una hora después de su reconstitución (Welborn et al., 2011).

Las vacunas no infecciosas (también llamadas vacunas muertas o inactivadas), contienen un organismo inactivado, pero antigénicamente intacto, o un antígeno natural o sintético derivado de ese organismo. Los organismos no infecciosos no son capaces de infectar, replicarse o inducir signos clínicos de enfermedad infecciosa. Generalmente para estimular una respuesta protectora requieren de múltiples dosis (incluso en animales adultos) y el uso de adyuvantes para aumentar su potencia. Estas vacunas se administran de forma parenteral y es menos probable que estimulen eficientemente ambas vías de la respuesta inmune, o sea la inmunidad humoral y la celular. Generalmente la protección generada es de menor duración comparándola con la inducida por las vacunas infecciosas (Day et al., 2016; Flores, 2007). Los adyuvantes comprenden una variedad de sustancias químicas que estimulan una reacción inflamatoria que determinará una mejor respuesta inmune al antígeno vaccinal. Si bien el hecho de que los microorganismos en vacunas muertas no pueden recuperar su virulencia, de allí que se les considere más seguras, los residuos de adyuvantes en ellas utilizados pueden permanecer en las áreas de vacunación en la mascota y ser responsables de reacciones inflamatorias y de hipersensibilidad (Welborn et al., 2011).

\section{Respuesta inmune e interferencias}

\section{con la vacunación}

Las vacunas consisten en microorganismos o fracciones de los mismos que, cuando son administradas a un animal inducen una respuesta inmunológica capaz de protegerlo frente al contacto posterior con el agente inicial. La respuesta inmune inducida resulta de la activación y expansión de células efectoras y células de memoria. Las vacunas deben ser eficaces para inducir protección y seguras para no producir enfermedad en el huésped. La eficacia de una vacuna está relacionada con la capacidad de estimular las células presentadoras de antígenos, seguido por la liberación de determinadas citoquinas (interleuquinas) y la estimulación de los linfocitos $\mathrm{T}$ cooperadores (Th), T citotóxicos (Tc) y $\mathrm{B}$, generando un número adecuado de células de memoria y efectoras específicas para el antígeno inoculado. El antígeno contenido en la vacuna debe permanecer un determinado período de tiempo, preferiblemente en lugares específicos del tejido linfoide, lo que permite la estimulación continua de las células del sistema inmune. Idealmente se espera que la vacuna sea capaz de conferir protección a largo plazo frente a una nueva exposición al agente, logrando una inmunidad de larga duración. La memoria inmunológica permitirá una respuesta inmune más intensa y duradera frente a una nueva exposición al patógeno (Flores, 2007).

La mayoría de las vacunas no infecciosas, independientemente de la edad del perro, requieren al menos dos dosis iniciales para inmunizar, separadas entre dos y seis semanas para asegurar que se ha desarrollado una inmunidad protectora y duradera. Cuando el intervalo entre las dos dosis iniciales de una vacuna no infecciosa excede las 6 semanas, se recomienda revacunar administrando dos dosis, separadas entre dos y seis semanas (Day et al., 2016). La vacuna contra la rabia es la excepción ya que el antígeno de la vacuna contra este virus es altamente inmunogénico. Para asegurar que los cachorros estén efectivamente inmunizados frente la mayoría de las vacunas no infecciosas, se recomienda administrar la primera dosis de vacuna en la serie inicial luego de las 12 semanas de edad, aunque frente a Leptospira se recomienda comenzar a las 8 semanas de edad. Después de la vacunación inicial, el inicio de la inmunidad protectora requiere más tiempo para desarrollarse con vacunas no infecciosas que con vacunas infecciosas. Para la mayoría de las vacunas no infecciosas, el tiempo mínimo desde la administración de la primera dosis en la serie inicial de vacunación hasta el desarrollo de inmunidad protectora es de 3 semanas (Welborn et al., 2011). Las vacunas infecciosas virales deben infectar las células del huésped para estimular la respuesta inmune. Estas vacunas son más eficaces porque pueden estimular los mismos tipos de inmunidad (celular, humoral, sistémica y local) que se producen por exposición natural. Asimismo, los organismos vaccinales están atenuados y no causan enfermedad. El inicio de la inmunidad después de la administración de una dosis única de vacuna infecciosa es de aproximadamente 1-7 días en ausencia de MDA y la inmunidad estimulada por las vacunas esenciales persiste por años. Incluso si se determina que los niveles de anticuerpos séricos están por debajo de los niveles "protectores", es probable que aún se mantenga la memoria inmunológica (linfocitos $\mathrm{T}$ y B) que permitirá que el animal esté protegido frente a la exposición con el patógeno (Welborn et al., 2011).

La vacunación de rutina en cachorros caninos y felinos se da en las primeras 16 semanas de vida, tiempo durante el cual hay un cambio considerable en el sistema inmunológico de estos animales. Es esencial para la vida neonatal que los cachorros recién nacidos obtengan protección inmunológica pasiva mediante la ingestión de inmunoglobulinas calostrales en las primeras horas luego del nacimiento, debido a que presentan una placentación endoteliocorial en la que existe una barrera relativamente impermeable para la transferencia in útero de las inmunoglobulinas maternas. El momento de la vacunación está determinado por el período de tiempo requerido para que las inmunoglobulinas adquiridas pasivamente se degraden, permitiendo así que se genere una respuesta inmune endógena por el neonato. La disminución de los anticuerpos maternales se puede diferenciar en 


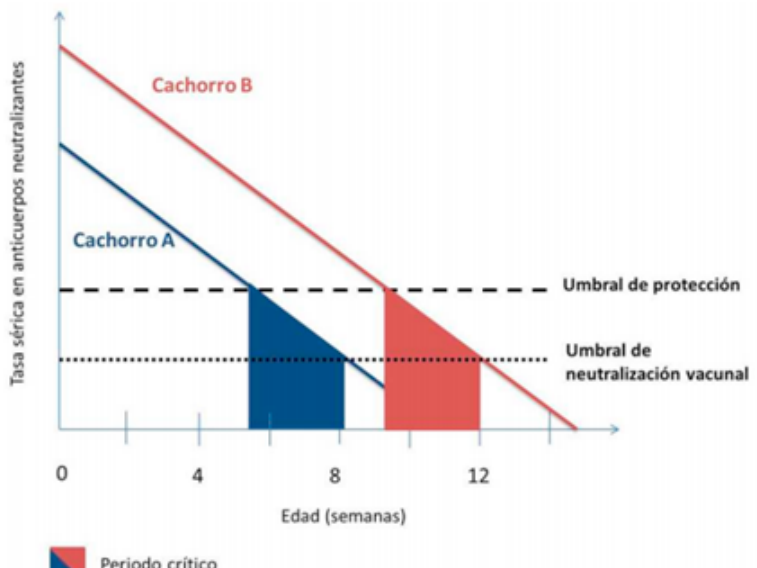

Periodo critico

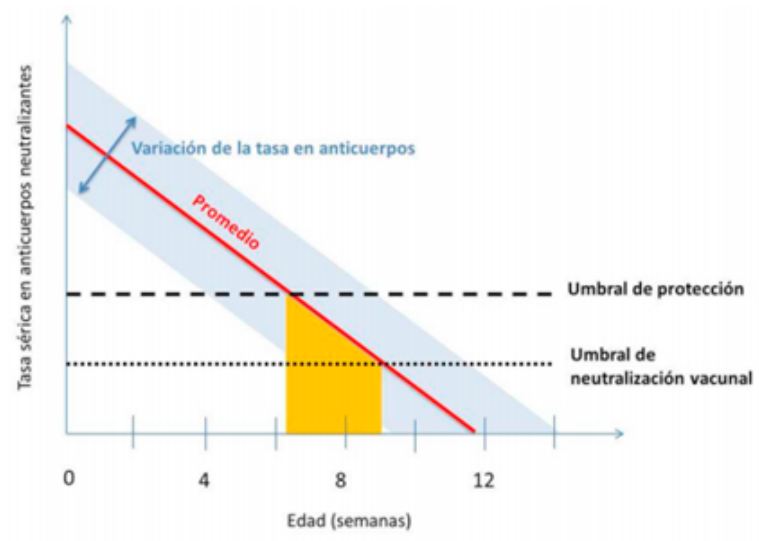

Periodo critico

A

B

Fig. 1. A) Curva que demuestra la disminución de la tasa sérica en anticuerpos neutralizantes o anticuerpos maternales (MDA) en función de la edad del cachorro. El periodo crítico es el periodo de tiempo durante el cual la tasa de MDA se encuentra entre el umbral de protección y el de neutralización de la vacuna, denominada "ventana de susceptibilidad". B) Esquema de la evolución de la tasa sérica en anticuerpos neutralizantes o anticuerpos maternales en dos cachorros A y B en función de la edad. Los cachorros pertenecen a la misma camada pero recibieron cantidades diferentes de calostro. Se observa que el período crítico es en dos momentos diferentes según la tasa sérica de anticuerpos maternales del inicio. Imagen tomada de Cadier J. (2015).

2 umbrales: el umbral de protección, bajo el cual el cachorro no tiene suficientes anticuerpos maternales para poder defenderse contra una infección natural; y el umbral de neutralización vaccinal, arriba del cual los anticuerpos maternales neutralizan las vacunas. Si se vacuna a un cachorro arriba de este umbral, la vacuna posiblemente sea neutralizada (Fig. 1A). Puede haber una variación considerable entre los cachorros de una misma camada en la eficiencia de la captación de las inmunoglobulinas calostrales, relacionado con el tamaño y la vitalidad del recién nacido individual y las habilidades maternas (Fig. 1B). Está documentado que los cachorros felinos no pueden absorber inmunoglobulinas maternales luego de las 16 horas de nacidos (Day, 2007; Cadier, 2015).

El calostro canino y felino es rico en IgG e IgA y ambas inmunoglobulinas están presentes en mayor concentración que en el suero de la perra y gata. A diferencia del calostro, la leche canina contiene significativamente más IgA que IgG, y esta IgA también está presente en mayor concentración que en el suero canino. Por el contrario, la leche felina tiene predominancia de IgG, siendo además las concentraciones de ambas (IgG e IgA) mayores en el calostro que en la leche (Day, 2007).

Al mismo tiempo que la inmunidad derivada de la madre protege a los cachorros de posibles infecciones durante el período neonatal, las concentraciones elevadas de inmunoglobulinas maternas inhiben el desarrollo de la respuesta inmune neonatal endógena. El momento en el que un cachorro se vuelve inmunocompetente sin interferencia inmunológica maternal (umbral de neutralización vaccinal), generalmente se considera que en promedio es entre las 6 y las 12 semanas de edad y está determinado por la concentración de inmunoglobulinas calostrales ingerida, las cuales disminuyen en un $50 \%$ cada 10 días aproximadamente (Tizard, 2013). Este momento del punto de vista inmunológico es denominado "ventana de susceptibilidad", y está carac- terizado por niveles de anticuerpos suficientemente bajos que permitirá una adecuada activación del sistema inmune del cachorro, pero por otro lado son insuficientes para protegerlo en caso que se exponga al patógeno en ese período. En general, los anticuerpos maternales son más efectivos en interferir con las vacunas infecciosas que con las vacunas no infecciosas (Day et al., 2016). Calcular el momento exacto en que los cachorros se vuelven inmunocompetentes sin interferencia inmunológica maternal no es posible, lo cual debe ser tenido en cuenta al momento de desarrollar los planes de vacunación (Day, 2007). Si bien existen métodos cuantitativos para medir los niveles de MDA, en la práctica diaria no se utilizan y generalmente la mayoría de los médicos veterinarios inician los planes alrededor de las 6 semanas de edad o incluso antes. Con esta práctica, puede ocurrir que aún existan niveles elevados de MDA en animales bien calostrados, lo que lleva a que sea una de las razones más comunes para el fracaso de la vacunación (Flores, 2007). Siguiendo este razonamiento se recomiendan entonces aplicar varias dosis en los animales cachorros, con el objetivo de poder escapar de la interferencia generada por las inmunoglobulinas maternas, en al menos una de las dosis aplicadas con las vacunas esenciales MLV.

En relación al envejecimiento de los animales, este está asociado con una disminución en la capacidad funcional del sistema inmunológico. En animales adultos se describen una serie de cambios morfológicos en los órganos linfoides primarios y secundarios, observándose una disminución significativa en la relación CD4:CD8. Se describe además una disminución de linfocitos $\mathrm{T}$ vírgenes y un aumento de linfocitos T CD4 + y CD8 + de memoria en animales viejos (HogenEsch y Thompson, 2010). Mediante mecanismos homeostáticos, el organismo mantiene el número de linfocitos $\mathrm{T}$ en sangre periférica dentro de límites normales, y debido a la disminución de los linfocitos T vírgenes, induce 

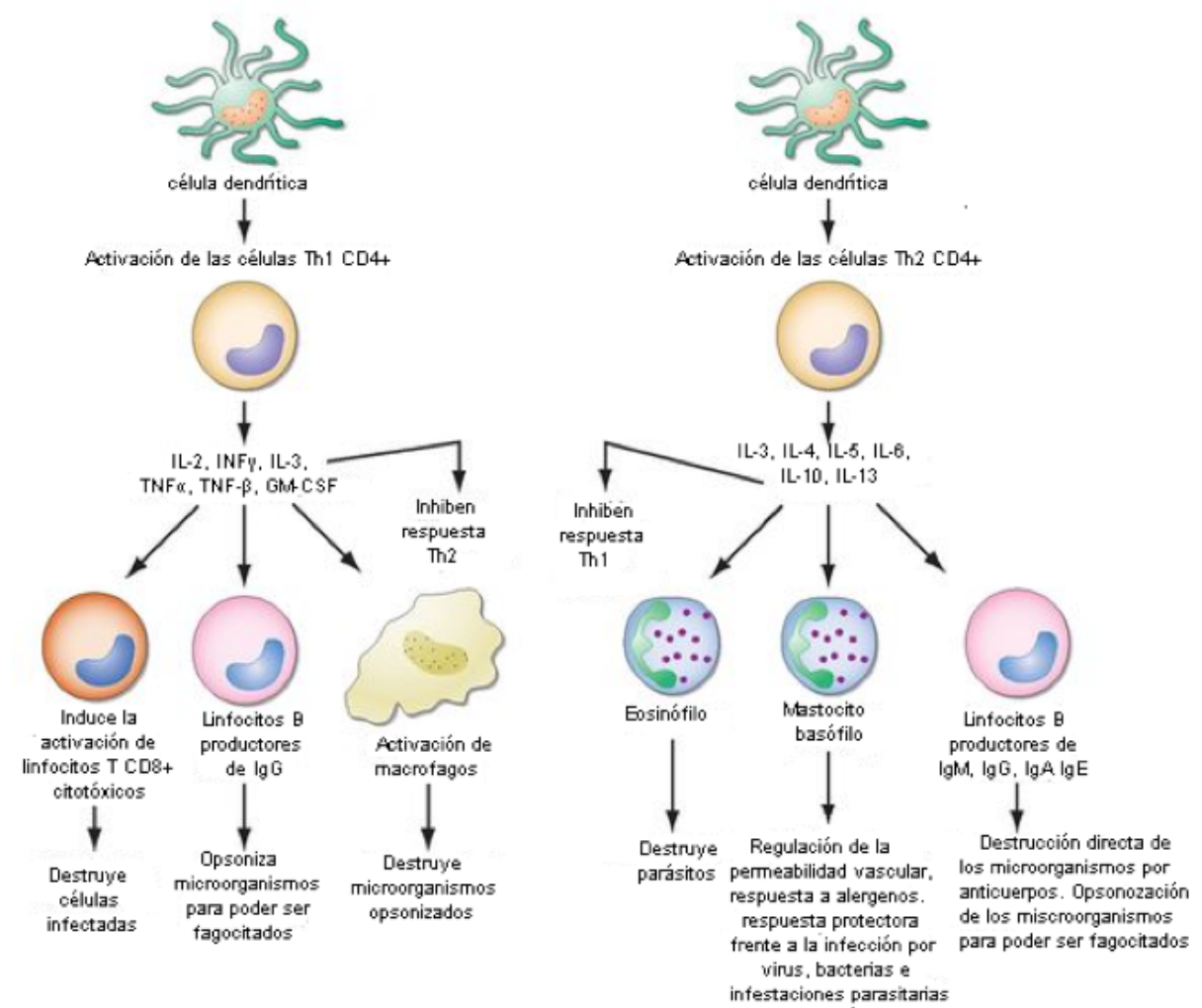

Fig. 2. Mecanismos efectores del sistema inmune y contra qué patógenos están dirigidos según el perfil de la respuesta de las células TCD4+. Imagen modificada extraída de: Kageyama, G. 2015. http://what-when-how.com/rheumatology/introductionto-the-immune-system-the-immune-system-in-health-and-disease-rheumatology-part-3/

la proliferación y prolonga la supervivencia de los linfocitos $\mathrm{T}$ residentes. La consecuencia de esta proliferación es que el envejecimiento de un individuo estaría asociado con la acumulación de células de memoria cerca de su límite de replicación. Estas, son incapaces de multiplicarse lo suficiente para producir una población clonal elevada y activar de manera eficiente las células efectoras del sistema inmune (Aspinall, 2000). Por tanto los estudios hasta la fecha sugieren que la respuesta primaria a las vacunas pueden verse comprometida en perros viejos, pero las respuestas de memoria permanecen intactas (HogenEsch y Thompson, 2010).

Por otro lado, se ha demostrado que las parasitosis severas en los animales, interfieren con la respuesta eficaz a los patógenos de la vacunación (Mojžišova et al., 2004; 2007, Haben et al., 2014). Esto se debe a que el sistema inmune presenta una inmunomodulación característica, relacionado con la respuesta de linfocitos T CD4 (también llamados T colaboradores) frente a los diferentes tipos de patógenos. Los diversos linajes de células T CD4 tienen cada una funciones muy diferentes. Por ejemplo, los linfocitos Th1 son cruciales para la inmunidad mediada por células y la producción de algunas subclases de inmunoglobulinas. Este perfil de respuesta es importante en la protección contra virus, algunas bacterias y protozoarios. Por otra parte, los linfocitos Th2 se relacionan más que nada con una respuesta de anticuerpos IgA, algunas subclases de IgG e IgE, con una notoria activación de mastocitos a nivel de las mucosas. Este perfil de respuesta promueve una "inmunidad de barrera" al incrementar la cantidad de moco en superficies epiteliales, respuesta que es inducida por distintos alérgenos, así como helmintos y otros parásitos extracelulares (Fig 2). Estos linajes o perfiles de respuestas inducidos por células $\mathrm{T}$ colaboradoras una vez que son activados, inhiben o suprimen otras ramas de la inmunidad, actuando como un balance inmunológico (Murphy et al., 2008). En ese contexto, un animal con una parasitosis importante tendrá activado un perfil de respuesta predominantemente Th2. Esta respuesta por lo tanto, inhibirá la activación eficiente de la rama Th1, esencial para el desarrollo de una inmunidad frente a las infecciones víricas (principales patógenos presentes en la vacunación canina y felina). Igualmente es importante señalar, que estos perfiles de respuestas no son absolutos, ya que una rama inhibe a la otra pero no la apaga por completo. Entonces se deben sopesar los riesgos de no vacunar a un cachorro con parasitosis dada la menor respuesta que este va a desarrollar frente a la vacunación y la posibilidad de contraer una infección por los patógenos considerados dentro de las vacunas esenciales. Si los riesgos a los que ese cachorro es expuesto superan los beneficios de esperar, se indica por lo tanto comenzar el plan de vacunación lo más pronto posible concomitantemente con el tratamiento antiparasitario, con el fin de lograr una respuesta poco robusta al inicio, pero suficiente para protegerlo del riesgo de exposición.

Con respecto a la intervención terapéutica con corticoides concomitante o cerca del momento de la vacunación, si bien se ha demostrado en algunos casos que el animal puede responder favorablemente (Puentes et al., 2016; Nara et al., 1979), lo que podría justificar su aplicación en determinadas situaciones, se recomienda de ser posible la revacunación 2 o más semanas lue- 


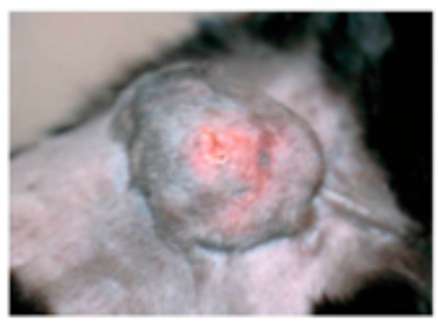

A

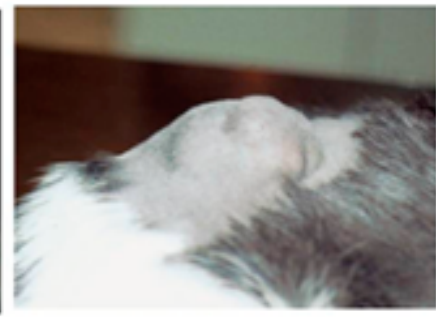

B

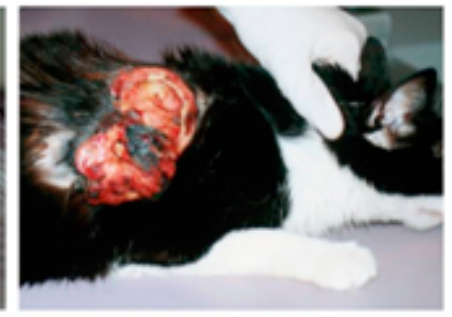

$\mathrm{C}$

Fig. 3. Sarcomas asociados con la vacunación en felinos. A) Sarcoma postvaccinal, aparentemente encapsulado en la pared costal. B) Sarcoma postvaccinal de aspecto lobulado en la región lumbar. C) Sarcoma postvaccinal ulcerado en la región interescapular. Imagen extraída de Menes y Martínez (2002).

go de finalizado el tratamiento (Welborn et al., 2011).

Por otro lado, se ha demostrado que ciertas deficiencias severas de vitaminas y oligoelementos (por ejemplo, Vitamina E / Se) pueden interferir con el desarrollo de una respuesta inmune protectora a ciertas vacunas, especialmente en cachorros. Por tanto, se deben subsanar las deficiencias nutricionales y el animal debe ser revacunado para asegurar que se produzca una inmunidad protectora (Welborn et al., 2011).

Finalmente, el efecto que las mutaciones virales inducen en la respuesta inmune montada hacia las diferentes vacunas es discutida, especialmente la respuesta frente a CPV-2 debido a la rápida aparición de nuevas variantes en poco tiempo (Cavalli et al., 2008; Pratelli et al., 2001). En ese sentido, si bien en Uruguay se han estudiados las variantes circulantes, encontrándose que CPV-2a y CPV-2c son las cepas más importantes (Pérez et al., 2012), no se ha demostrado claramente hasta la fecha que las cepas vaccinales utilizadas sean ineficaces contra los nuevos genotipos de virus circulantes en los animales (Puentes, 2012).

\section{Reacciones adversas a las vacunas empleadas en caninos y felinos}

Las reacciones adversas se definen como cualquier efecto secundario o consecuencia no deseada (incluida la falta de respuesta) asociadas con la administración de una vacuna. Al ser productos biológicos las reacciones adversas pueden instalarse rápidamente y persistir durante varias horas a días. Generalmente son autolimitantes, pero ocasionalmente pueden pasar a ser patologías severas. Es importante destacar que las reacciones adversas a la vacunación son excepcionalmente raras.

Las reacciones adversas documentadas hasta la fecha incluyen: síntomas de anorexia, letargia, fiebre, dolor, hipersensibilidad tipo 1,2 y 3 , inflamación exacerbada, nódulos y masas, alopecias o abscesos en el sitio de vacunación (Meyer, 2001).

La virulencia residual de las vacunas vivas modificadas puede causar reacciones adversas en los animales vacunados. Si se vacuna una perra preñada con una vacuna viva modificada frente a CPV-2, se ha visto que puede provocar una miocarditis no supurativa en los cachorros (Povey y Carmen, 1997). Cabe destacar que la reversión a la virulencia de los patógenos atenuados presentes en las vacunas vivas modificadas utilizadas en la actualidad, son extremadamente raros o inexistentes (Welborn et al., 2011).

Por otra parte, las vacunas (de cualquier tipo) se han relacionado con la patogenia del sarcoma del sitio de inyección felina (FISS) (Fig 3), especialmente con las vacunas de ViLeF y rabia con adyuvantes. Aunque la patogenia del FISS sigue sin demostrarse, la creencia actual es que una reacción inflamatoria crónica localizada inicia la transformación maligna de las células mesenquimales y que este proceso tiene una base genética. La naturaleza infiltrante de estos tumores significa que a menudo es necesaria la resección quirúrgica radical (Day et al., 2016). Actualmente se estima la prevalencia de la FISS de 1 de cada 5,000 a 12,500 gatos vacunados (Dean et al., 2013; Gobar y Kass 2002). La American Animal Hospital Association (AAHA) recomienda vacunar a los felinos en los miembros tan distal como sea posible por vía subcutánea (por ejemplo, rabia en miembro posterior derecho) (Welborn et al., 2011).

\section{Recomendaciones para la vacunación de caninos}

En términos generales, se debe comenzar el plan de vacunación contra los patógenos esenciales a las 6-8 semanas de edad, revacunar cada 2-4 semanas hasta las 16 semanas de edad. Luego el booster (o revacunación) se debe realizar a los 6 meses (26 semanas) o al año de edad. De esta forma se asegura que el cachorro esté libre de anticuerpos maternales al momento de dar como mínimo una dosis de vacuna esencial MLV. Una vez terminado el plan inicial de vacunación, se recomiendan vacunaciones cada tres años. La inmunización en los caninos adultos con las vacunas esenciales MLV, debe realizarse con una sola dosis y luego vacunaciones cada tres años (Day et al., 2016).

Por otro lado, la vacunación frente al virus de la Rabia se debe administrar a los cachorros a las 12 semanas de edad como mínimo. Y para la vacunación de caninos adultos, una dosis es considerada suficiente (Day et al., 2016).

Para el virus de la Parainfluenza canina (CPiV), se sugiere ad- 

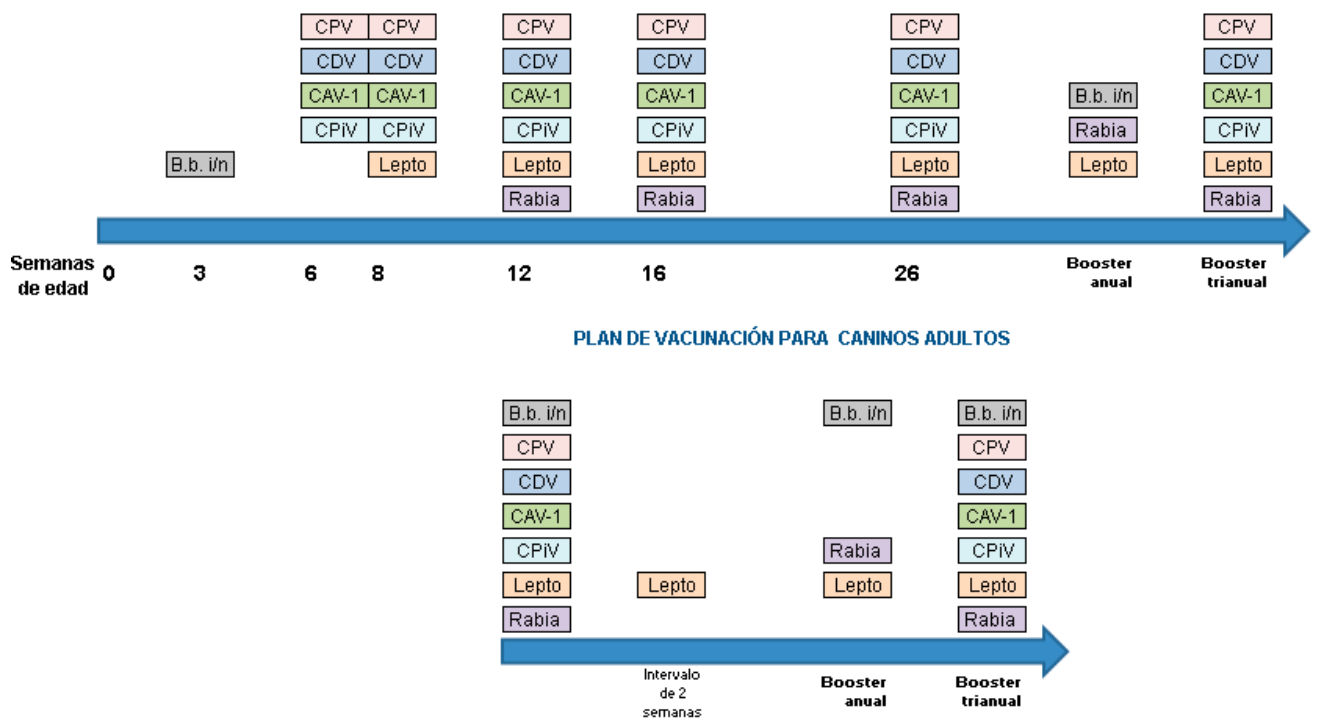

Fig. 4. Esquema de plan de vacunación recomendado para caninos. El mismo puede variar dependiendo el intervalo seleccionado por el clínico/a. Siglas: CPV-2 (Parvovirus Canino tipo 2), CDV (Virus de Distemper Canino), CAV-1 (Adenovirus Canino tipo 1), CPiV (Virus de la Parainfluenza canina), Rabia (Virus de la Rabia), Lepto (Leptospira interrrogans),

B.b. i/n (Bordetella bronchiseptica intranasal).

ministrar la vacuna intranasal preferentemente. En cachorros se recomienda el mismo plan que el recomendado para las vacunas esenciales. En cambio, en los caninos adultos una dosis es suficiente, pero se debe administrar un booster anual.

Para proteger a los caninos frente a Bordetella bronchiseptica se han diseñado vacunas vivas atenuadas de administración intranasal. Esta se debe administrar una sola dosis tanto a adultos como a los cachorros a las 3 semanas de vida y luego booster anuales. La presentación parenteral, contiene al patógeno inactivado y se recomienda 2 dosis separadas por 2-4 semanas tanto en adultos como en cachorros, a partir de las 6-8 semanas de edad. Se debe administrar un booster anual (Day et al., 2016).

Para la vacunación frente a Leptospira interrrogans, se recomienda en cachorros una primera dosis a las 8 semanas de edad y luego revacunar a las 2-4 semanas y en adultos se deben administrar 2 dosis separadas por 2-4 semanas. Se recomienda revacunar anualmente a todos los animales con una única dosis (Day et al., 2016). Finalmente la vacunación frente a Coronavirus Canino $(\mathrm{CCOV})$ no es recomendada ya que la infección por este virus es generalmente subclínica. Asimismo las vacunas inactivadas, como las que se disponen en plaza en nuestro país, son poco efectivas en la protección frente a este patógeno (Decaro y Buonavoglia, 2008). Hace algunos años se identificó una cepa de CCoV altamente patógena, causando una enfermedad sistémica que generalmente lleva a la muerte a los animales en pocos días (Buonavoglia et al., 2006), denominado Coronavirus pantrópico. Las vacunas actuales son fabricadas con la cepa $\mathrm{CCoV}$ entérica. Esta cepa produce una inmunidad débil frente a la variante pantrópica y sumado a que las mismas vienen inactivadas, resulta en la no protección de los caninos frente a esta nueva variante patógena (Decaro y Buona- voglia, 2008).

Finalmente y considerando posibles situaciones limitadas, donde un canino pueda ser vacunado una sola vez, esa vacunación debe ser con vacunas esenciales a las 16 semanas de edad o más. En la Fig. 4 se resume el plan de vacunación recomendado para caninos en nuestro país.

\section{Recomendaciones para la vacunación de felinos}

En nuestro país se encuentran disponibles comercialmente únicamente las vacunas esenciales frente a Virus de la panleucopenia felina (FPV), Calicivirus felino (FCV) y Herpesvirus felino-1 (FHV-1) y la vacuna frente al virus de la Rabia.

Es importante tener presente que la protección conferida por la vacuna frente FPV es más robusta y de mayor duración que la inducida por las vacunas de FCV y FHV-1. Las vacunas contra FCV se han diseñado para producir inmunidad cruzada contra múltiples cepas de FCV; sin embargo, todavía es posible que la infección y la enfermedad se produzcan en los animales adultos vacunados. Las vacunas contra FHV-1 no protegen contra la infección por el virus virulento, pero sí de la enfermedad clínica. Por tanto, es probable que un animal inmunizado se infecte y se establezca una infección latente con la posibilidad de reactivación durante los periodos de estrés severo. Existen por tanto 2 tipos de inmunidad conferidas por las vacunas felinas. La “inmunidad esterilizante", la cual previene la infección posterior frente a esos patógenos, evitando así el desarrollo de la enfermedad. Este es el caso de las vacunas frente a FPV y el virus de la 

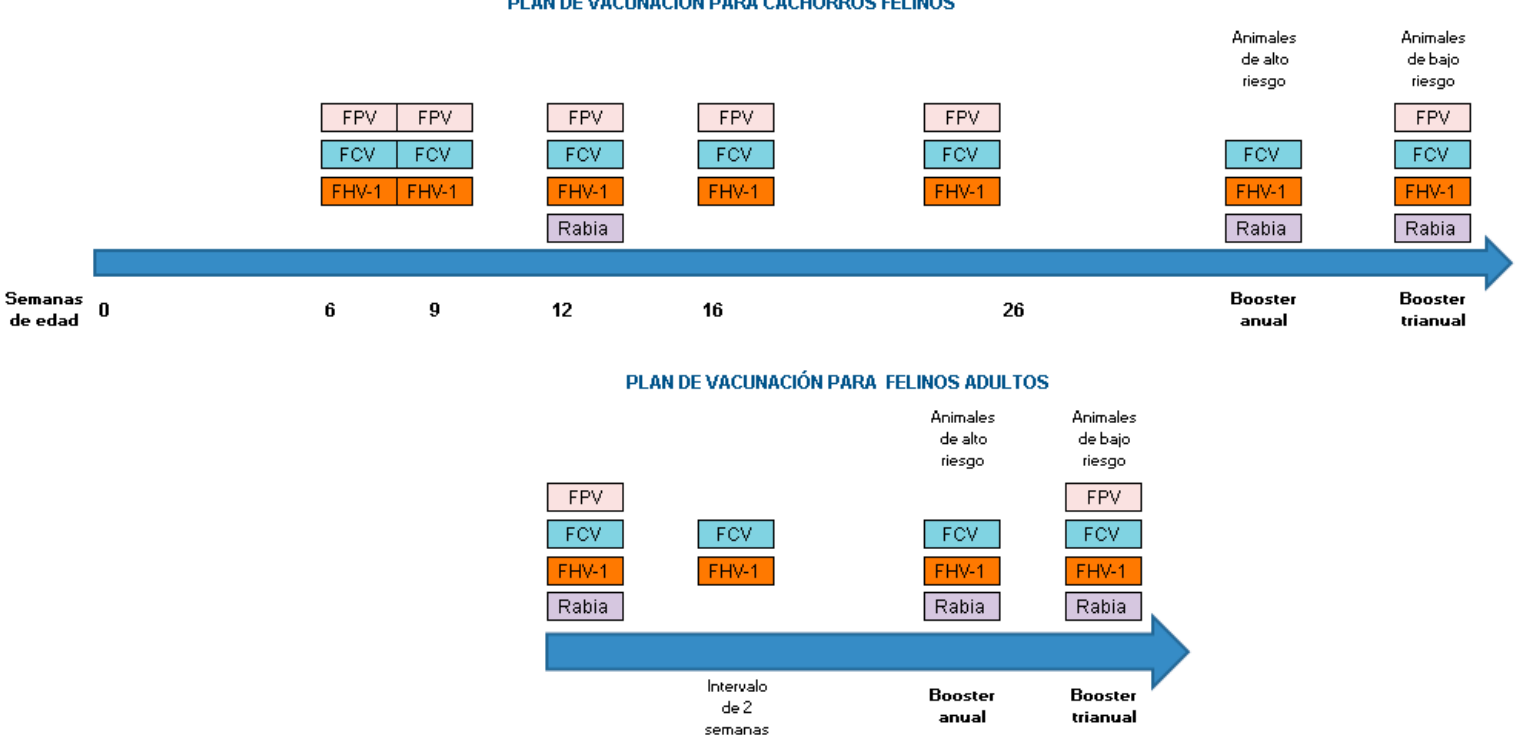

Fig. 5. Esquema de plan de vacunación recomendado para felinos. El mismo puede variar dependiendo el intervalo seleccionado por el clínico/a. Siglas: FPV (Virus de la panleucopenia felina), FCV (Calicivirus felino), FHV-1 (Herpesvirus felino-1), Rabia (Virus de la Rabia).

Rabia. Por otro lado, existe una "inmunidad protectora pero no esterilizadora”, es decir la vacunación permite la infección pero reduce la gravedad de la enfermedad clínica. Este es el caso de las vacunas frente a FCV y FHV-1 (Scherk et al., 2013). Por otro lado, se debe considerar que la inmunidad más robusta conferida por las vacunas frente a FCV y FHV-1 se produce en el plazo de 3 meses después de la inmunización. Esto es importante tenerlo presente, en caso que se vaya a mover al animal o exponerlo a situaciones de riesgo (Day et al., 2016).

Para la vacunación de cachorros felinos con patógenos esenciales se debe comenzar a partir de las 6-8 semanas de edad y luego repitiendo la vacunación cada 2-4 semanas hasta las 16 semanas de edad o más. Se debe realizar un booster a los 6 meses (26 semanas) de edad para asegurar el desarrollo de una respuesta inmune protectora en cualquier gatito que pueda no haber respondido adecuadamente a ninguna de las vacunas de la serie básica primaria. Los gatos que han respondido a la vacunación con vacunas MLV básicas mantienen una inmunidad sólida contra FPV durante muchos años (Day et al., 2016). Por otro lado, la inmunidad lograda contra la FCV y FHV-1 con las vacunas comerciales disponibles, no es tan eficaz y por lo tanto gatos adultos de "bajo riesgo" deben ser revacunados con vacunas MLV esenciales a intervalos de 3 años o más. Para los gatos de "alto riesgo" se podría considerar la vacunación frente a FPV cada 3 años, pero frente a FCV y FHV-1 se debe revacunar anualmente (Day et al., 2016). En nuestro país las vacunas comercializadas son multivalentes (conteniendo estos tres patógenos esenciales en una sola presentación), lo que dificulta al clínico/a realizar una vacunación diferenciada en los felinos.

En cuanto a la vacunación de animales adultos, un gato con historia de vacunación desconocida debe recibir una sola dosis de la vacuna MLV esencial contra FPV para generar una respuesta inmune protectora. Frente a FHV-1/FCV debe recibir dos dosis de la vacuna MLV, separadas por 2-4 semanas para montar una respuesta inmune eficaz (Day et al., 2016).

La vacuna de la Rabia debe ser administrada una única dosis a partir de las 12 semanas de edad y revacunar un año después (Day et al., 2016).

Finalmente y considerando posibles situaciones limitadas, donde un felino pueda ser vacunado una sola vez, esa vacunación debe ser con vacunas esenciales a las 16 semanas de edad o más. En la Fig 5 se resume el plan de vacunación recomendado para felinos en nuestro país.

\section{Vacunación en refugios}

Los refugios se caracterizan por tener poblaciones de diferentes orígenes y estatus sanitario desconocidos, siendo por tanto susceptibles a contraer enfermedades infecciosas, las cuales en el ambiente refugio son prácticamente imposibles de erradicar. Generalmente cuentan con recursos financieros limitados, por tanto el protocolo mínimo de vacunación en esta situación sería una sola administración de las vacunas esenciales tanto a los perros o gatos que ingresen antes o en el momento del ingreso al refugio (Day et al., 2016).

En caso de contar con los recursos necesarios, los cachorros ingresados pueden comenzar el plan de vacunación a las 4-6 semanas de edad y revacunar cada 2 semanas hasta llegar a las 20 semanas de edad, dado el alto riesgo al que están expuestos. En los animales adultos se recomienda seguir las instrucciones plasmadas en esta guía, es decir vacunación cada tres años frente a los patógenos esenciales caninos. Para los felinos se recomienda 
vacunación anual frente a FHV-1/FCV (ya que se consideran animales de alto riesgo) y cada tres años frente a FPV. Ambas especies deben ser vacunadas frente al virus de la Rabia.

Consideramos esencial destacar la importancia de la vacunación como primera medida sanitaria al ingreso de animales en centros de acogida o refugios, independientemente de su estado de salud (presencia de sarnas, endoparasitosis, desnutridos, etc). El riesgo de contraer enfermedades potencialmente mortales es muy alto en estos lugares. En la medida que los recursos lo permitan, se sugiere revacunar a las 2 semanas.

Finalmente, cabe señalar que las vacunas deber administradas por la vía parenteral subcutánea permitiendo una mejor exposición y presentación al sistema inmune de los patógenos contenidos en la vacuna. En la revisión bibliográfica realizada en el diseño de estas recomendaciones no se encontró evidencias científicas que respalde que otras vías parenterales (como ejemplo la intramuscular), generen una respuesta más rápida o más robusta.

\section{Referencias bibliográficas}

Aspinall, R. (2000). Longevity and the immune response. Biogerontology, 1, 273-278.

Buonavoglia, C., Decaro, N., Martella, V., Elia, G., Campolo, M., Desario, C., Castagnaro, M., Tempesta, M. (2006). Canine coronavirus highly pathogenic for dogs. Emerg Infect Dis, 12, 492-494.

Cadier, J. (2015). Actualizaciones en vacunología canina: ¿cómo adaptar el protocolo vacunal a cada animal? La Granja: Rev Cien Vida, 22(2), 58-64.

Cavalli, A., Martella, V., Desario, C., Camero, M., Bellacicco, A. L., De Palo, P., Decaro, N., Elia, G., Buonavoglia, C. (2008). Evaluation of the Antigenic Relationship among Canine Parvovirus Type 2 Variants. Clin Vaccine Immunol, 15, 534-539.

Day, M. J. (2007). Immune System Development in the Dog and Cat. J Comp Path, 137, S10-S15.

Day, M. J., Horzinek, M. C., Schult, R. D., Squires, R. A. (2016). WSAVA Guidelines For The Vaccination Of Dogs And Cats. J Small Anim Pract, 57(1), E1-E45.

Dean, R. S., Pfeiffer, D. U., Adams, V. J. (2013). The incidence of feline injection site sarcomas in the United Kingdom. BMC Vet Res, 9, 17.

Decaro N, Buonavoglia C. (2008) An update on canine coronaviruses: Viral evolution and pathobiology. Vet Microbiol, 132(3-4), 221-234.

Eliopulos, N., Finger, P., Nunes, C., Castro, C., Moreno, J.,
Hubner, S., Puentes, R. (2010). Immune Response to canine Parvovirus (CPV): Comparision of antibodies to CPV-2 and CPV-2c in unvaccinated dogs. En XXI Encontro Nacional de Virología, V Encontro de Virología do Mercosul. Gramado: Sociedade Brasileira de Virologia.

Eliopulos, N, Suzuki, K, Puentes, R. (2013). Variables que interfieren en la respuesta inmune contra rabia en perros vacunados a campo. En $1{ }^{\circ}$ Congreso Internacional de Veterinaria. Montevideo: Sociedad de Medicina Veterinaria del Uruguay.

Flores, E. F. (2007). Virologia Veterinária. Santa Maria: Ed. da UFSM.

Franco, G., Puentes, R. (2011). Detección y aislamiento de Parvovirus canino a partir de vacunas comerciales. En VII Jornadas Técnicas de la Facultad de Veterinaria. Montevideo: Facultad de Veterinaria.

Gobar, G. M., Kass, P. H. (2002) World Wide Web-based survey of vaccination practices, postvaccinal reactions, and vaccine site-associated sarcomas in cats. J Am Vet Med Assoc, 220, 1477-1482.

Haben, I., Hartmann, W., Breloer, M. (2014). Nematode-Induced Interference with Vaccination Efficacy Targets Follicular T Helper Cell Induction and Is Preserved after Termination of Infection. PLoS Negl Trop Dis, 8(9), e3170.

HogenEsch, H., Thompson, S. (2010). Effect of Ageing on the Immune Response of Dogs to Vaccines. J Comp Path, 142, S74-S77.

Machin, F., Guerrero, H., Paggio, J., Puentes, R. (2013). Encuesta sobre la situación actual de parvovirus canino en clínicas veterinarias de la ciudad de Montevideo. En $1{ }^{\circ}$ Congreso Internacional de Veterinaria. Montevideo: Sociedad de Medicina Veterinaria del Uruguay.

Maya, L., Calleros, L., Francia, L., Hernández, M., Iraola, G., Panzera, Y., Sosa, K., Pérez, R. (2013). Phylodynamics analysis of canine parvovirus in Uruguay: evidence of two successive invasions by different variants. Arch Virol, 158(6), 1133-41.

Menes, I., Martínez, E. M. (2002). Sarcomas felinos asociados a vacunación. Consulta Difus Vet, 94, 83-94.

Meyer, K. (2001). Vaccine-associates adverse events. Vet Clin North Am Small Anim.Pract, 31(3), 493-514.

Mojžišova, J., Hromada, R., Paulik, S., Ondrašovič, M., Bajova, V. (2004). Immune response and immunomodulatory effect of levamisole in mmunosuppressed dogs vaccinated against parvovirosis. Bull Vet. Inst Pulawy, 48, 93-97. 
Mojžišova, J., Süli, J., Goldová, M., Bajová, V., Švrcek, S. (2007). The effect of endoparasitism on the immune response to antirabies vaccination in puppies. Acta Parasitol, 52(2), 176-180.

Moreno, J., Burghi, N., Piaggio, J., Puentes, R. (2012). Respuesta inmune de caninos vacunados contra el virus de la rabia. Veterinaria (Mont.), 48(186), 19-22.

Murphy, K., Travers, P., Walport, M. (2008). Inmunobiología de Janeway (7a. ed.). Mexico: McGraw-Hill Interamericana.

Nara, P. L., Krakowka, S., Powers, T. E. (1979). Effects of prednisolone on the development of immune responses to canine distemper virus in beagle pups. Am J Vet Res, 40, 1742-1747.

Panzera, Y., Sarute, N., Iraola, G., Hernández, M., Pérez, R. (2015). Molecular phylogeography of canine distemper virus: Geographic origin and global spreading. Mol Phylogenet Evol, 92, 147-54.

Pérez, R., Bianchi, P., Calleros, L., Francia, L., Hernández, M., Maya, L., Panzera, Y., Sosa, K., Zoller, S. (2012) Recent spreading of a divergent canine parvovirus type $2 \mathrm{a}(\mathrm{CPV}-2 \mathrm{a})$ strain in a CPV-2c homogenous population. Vet Microbiol, 155 214-219.

Povey, R. C., Carman P. S. (1997). Risks of vaccination. En Veterinary vaccinology (pp. 546-551). New York: Elsevier.

Pratelli, A., Cavalli, A., Martella, V., Tempesta, M., Decaro, N., Carmichael, L. E., Buonavoglia, C. (2001). Canine Parvovirus (CPV) Vaccination: Comparison of Neutralizing Antibody Response in Pups after Inoculation with CPV2 or CPV2b Modified Live Virus Vaccine. Clin Diagn Lab Immunol, 8, 612-615.

Puentes, R. (2012). Parvovirosis Canina: situación actual y protección de las vacunas contra las nuevas variantes virales circulantes en la región. Veterinaria (Montev.), 48(185), 5-10.

Puentes, R., Eliopulos, N., Finger, P., Castro, C., Nunes, C., Furtado, A., Franco, G., Hubner, S. (2010). Detección viral en cachorros con diagnóstico presuntivo de Parvovirus canino (CPV). Veterinaria (Montev.), 46(177-180), 47-49.

Puentes, R., Eliopulos, N., Pérez, R., Franco, G., Sosa, K., Bianchi, P., Furtado, A., Hübner, S. O., Esteves, P. A. (2012). Isolation and characterization of canine parvovirus type $2 \mathrm{c}(\mathrm{cpv}-2 \mathrm{c})$ from symptomatic puppies. Braz J Microbiol, 43(3), 1005-1009.

Puentes, R., Calero, D., Caresani, B., Eliopulos, N., Suárez, G., Silva, A. C. R, Batista, H. B. C. R. (2016). Respuesta a la vacunación contra el virus de la rabia en perros inmunizados durante el acto quirúrgico o bajo efecto de drogas inmunomoduladoras. Veterinaria (Montev.), 52(203), 18-24.
Sarute, N., Delgado, M. V., Carrau, L., Benech, A., Francia, L., Pérez, R., Panzera, Y. (2014). First genome sequence of a canine distemper virus strain from South america. Genome Announc, 2(5), e01009-14.

Scherk, M. A., Ford, R. B., Gaskell, R. M., Hartmann, K., Hurley, K. F., Lappin, M. R., Levy, J. K., Little, S. E., Nordone, S. K., Sparkes, A.H. (2013). The immune response to vaccination. A brief review. J Feline Med Surg, 15, Supplementary File.

Tizard, I. (2013). Veterinary Immunology (9a. ed.). St. Louis: Saunders, Elsevier.

Welborn, L., DeVries, J., Ford, R., Franklin, R., Hurley, K., McClure, K., Paul, M., Schultz, R. (2011). 2011 AAHA Canine Vaccination Guidelines. J Am Anim Hosp Assoc, 47(5), 1-42.

\section{Notas de contribución:}

Ambos autores participaron en igual medida en la recopilación y jerarquización de los datos y redacción de la revisión.

El editor Cecilia Cajarville aprobó ese artículo. 